\title{
J-integral evaluation of cold worked and aged TiNbSn alloys as a function of alloy content
}

\author{
Thiago Azevedo ${ }^{1}$, Tiago Lima ${ }^{2}$, Weslley Sampaio ${ }^{1}$, and Sandro Griza ${ }^{3}$ \\ ${ }^{1}$ Instituto Federal de Alagoas \\ ${ }^{2}$ SENAI CIMATEC Technology College \\ ${ }^{3}$ Universidade Federal de Sergipe
}

July 28, 2020

\begin{abstract}
The present study evaluates the J-integral resulting from cold rolling and aging treatments applied to TiNbSn alloys comprising different contents of $\mathrm{Nb}(35 \%$ and $42 \%)$ and $\mathrm{Sn}(0 \%$ and $2.5 \%)$. The alloys were arc melted, homogenized, solution heat treated, cold-rolled and aged at $400{ }^{\circ} \mathrm{C}$ during different aging times. A set of characterization tests, including microstructural, scanning electron microscopy, work hardening coefficients and fracture analysis were performed. The cold worked alloys with the highest $\mathrm{Nb}$ content showed the highest toughness. The addition of $\mathrm{Nb}$ in these alloys is beneficial for toughness since $\mathrm{Nb}$ stabilizes the $\beta$ phase. In alloys with lower $\mathrm{Nb}$ content, cold forming causes a greater amount of $\alpha$ " and this disfavors toughness. Aging caused a reduction in the alloys' toughness, since the formation of precipitates in aging causes shallower and smaller dimples in the fracture, corroborating to a lower toughness.
\end{abstract}

\begin{abstract}
The present study evaluates the J-integral resulting from cold rolling and aging treatments applied to TiNbSn alloys comprising different contents of $\mathrm{Nb}(35 \%$ and $42 \%)$ and $\mathrm{Sn}(0 \%$ and $2.5 \%)$. The alloys were arc melted, homogenized, solution heat treated, cold-rolled and aged at $400{ }^{\circ} \mathrm{C}$ during different aging times. A set of characterization tests, including microstructural, scanning electron microscopy, work hardening coefficients and fracture analysis were performed. The cold worked alloys with the highest $\mathrm{Nb}$ content showed the highest toughness. The addition of $\mathrm{Nb}$ in these alloys is beneficial for toughness since $\mathrm{Nb}$ stabilizes the $\beta$ phase. In alloys with lower $\mathrm{Nb}$ content, cold forming causes a greater amount of $\alpha$ " and this disfavors toughness. Aging caused a reduction in the alloys' toughness, since the formation of precipitates in aging causes shallower and smaller dimples in the fracture, corroborating to a lower toughness.
\end{abstract}

Keywords: TiNbSn alloys, aging, J-integral, work hardening coefficient, fracture mechanics.

* Corresponding author: thiago.azevedo@ifal.edu.br (T.F. Azevedo).

Introduction

TiNbSn alloys have aroused interest due to their good relation of mechanical properties for application in biomaterials, shape memory, superelasticity, resilient elements, among others [1-5]. The development of new $\mathrm{Ti}$ alloys aims to obtain materials with good relation of mechanical properties applied in structural and biomedical areas [6]. Ti alloys with the addition of niobium and tin have been gaining prominence due to their relation of properties and performance [1-9]. The researchers seek to develop alloys whose high strength-to-weight ratio, low modulus of elasticity, high resistance to corrosion and fatigue and good ductility can be easily manipulated through thermomechanical processes. 
The production and control of mechanical properties of these alloys involve thermomechanical treatments of hot [6-9] and cold [10] plastic deformation, solution heat treatment and aging [10]. By combining these methods, it is possible to highlight some properties over others. For example, cold worked alloys have a high relation between tensile strength and modulus of elasticity, in addition to high ductility [10]. On the other hand, the aging of these same alloys can further increase tensile strength, but with a significantly adverse impact on ductility reduction and elasticity modulus increase [10].

The fracture toughness of the new alloys is also an important parameter to be investigated. Some studies have allowed obtaining $\mathrm{K}_{\mathrm{lc}}$ of some of these alloys that fit in the elastic linear fracture mechanics regime [11]. However, the application of J-integral can have an advantage because it is possible to obtain the fracture mechanics parameter comparable to both considerably ductile alloys and alloys that follow the elastic linear regime.

J-integral is an energy conservation theorem formulated by Eshelby, which represents the variation rate of potential energy in relation to the length of the crack [12]. The J-integral is obtained by the sum of the elastic component and the plastic component of J, according to Eq. 1. Both parts are based on the area below the load curve versus displacement, recorded during the crack opening test to obtain the fracture toughness.

$J=J_{\mathrm{el}}+J_{\mathrm{pl}}$ (Eq. 1)

Where:

$J_{\mathrm{el}}=$ Elastic component of $\mathrm{J}$

$J_{\mathrm{pl}}=$ Plastic component of $\mathrm{J}$.

The calculation of the J-integral by the basic method (ASTM E1820) is given by Eq. 2:

$J=\frac{K\left(1-\nu^{2}\right)}{E}+\frac{\eta_{\mathrm{pl}} A_{\mathrm{pl}}}{B b_{0}}($ Eq. 2)

Where: $A_{\mathrm{pl}}=$ area under force versus displacement record $K=$ stress-intensity factor $; \nu=$ Poisson's ratio; $E=$ Young's modulus; $\eta_{\mathrm{pl}}=$ Constant, $(1.9) ; B=$ Specimen thickness; $b_{0}=$ uncracked ligament, $\left(\mathrm{W}-a_{0}\right) ; W=$ Specimen width $; a_{0}=$ Initial crack length.

When obtaining the plastic area of $J$ by controlling the Crack Mouth Opening Displacement (CMOD), $\eta_{\mathrm{pl}}$ assumes a resulting value of Eq. 3 for Single Edge Notched Bend (SENB) specimen.

$\eta_{\mathrm{pl}}=3,667-2,199\left(\frac{a_{0}}{W}\right)+0,437\left(\frac{a_{0}}{W}\right)^{2}$ (Eq. 3)

However, studies on the properties of elastoplastic fracture mechanics for the TiNbSn alloy system are not widely disseminated in the literature. Therefore, studies of these characteristics are necessary to broaden the understanding of the performance of these new alloys. This study aims to observe the elastoplastic behavior of cold worked and aged TiNbSn alloys, by calculating the values of the J-integral, according to different $\mathrm{Nb}$ contents (35\% and $42 \%$ wt.) and Sn (0\% and $2.5 \%$ wt.).

2. Materials and methods

The high-purity raw materials $(99.99 \% \mathrm{Ti}, 99.50 \% \mathrm{Nb}$ and $99.98 \% \mathrm{Sn})$ were arc melted under controlled argon atmosphere to produce the Ti35Nb2.5Sn, Ti42Nb2.5Sn and Ti42Nb alloys.

The alloys were homogenized at $1000{ }^{\circ} \mathrm{C}$ for $4 \mathrm{~h}$ and experienced slow cooling inside the furnace (model FL1300 Maitec). The solution heat treatment was performed at $900{ }^{\circ} \mathrm{C}$ for 15 minutes, followed by ice cooling $\left(0{ }^{\circ} \mathrm{C}\right)$ to ensure $\beta$ phase maintenance and higher ductibility of the alloys. The ingots were hot-rolled at $850^{\circ} \mathrm{C}$ to uniform the plate thickness, and experienced solution heat treatment followed by ice cooling at $0^{\circ} \mathrm{C}$. Then, cold rolling was performed on the plates applying conventional deformation of $0.55(55 \%)$, to refine the microstructure. 
After performing the mechanical processing described above, the Ti422 and Ti420 alloys were aged at 400 ${ }^{\circ} \mathrm{C}$ for $48 \mathrm{~h}$ and the Ti352 alloy was aged at $400{ }^{\circ} \mathrm{C}$ for $72 \mathrm{~h}$, seeking to achieve greater hardness in the peak aging of each alloy, according to Azevedo, et. al. [9]. Figure 1 shows the procedures of thermomechanical treatments used to produce each sample. The following alloys were studied:

Ti352C - Ti35Nb2.5Sn, cold rolled alloy;

Ti352A - Ti35Nb2.5Sn, alloy aged at peak-aged stage;

Ti422C - Ti42Nb2.5Sn, cold rolled alloy;

Ti422A - Ti42Nb2.5Sn, alloy aged at peak-aged stage;

Ti420C - Ti42Nb, cold rolled alloy;

Ti420A - Ti42Nb, alloy aged at peak-aged stage.

Figure 1 - Steps in the alloys processing. Cold rolling process (above) and cold rolling followed by aging at $400^{\circ} \mathrm{C}$ (below).

\subsection{Microstructures}

The microstructures of the samples in the rolling direction of the plates were analyzed. The metallographic samples were polished in alumina solution (particle size: 0.5 micrometers). The chemical etching to reveal the microstructures was achieved through Kroll's solution ( $12 \mathrm{ml} \mathrm{HNO}_{3}, 6 \mathrm{ml} \mathrm{HF}$ and $82 \mathrm{ml} \mathrm{H}_{2} \mathrm{O}$ ). The microstructural aspects were observed through Optical Microscopy (Zeiss Axioscope A1) and Scanning Electron Microscopy (SEM Jeol-JCM-5700 Carry Scope).

\subsection{Work hardening coefficient}

The method described in the literature [9] was used in this study to obtain the work hardening coefficients of the cold worked and aged TiNbSn alloys. The method consists on the transformation of the conventional tensile curves of the alloys under study, previously presented [9] into a true curve. The true stress $(\sigma)$ and true strain $(\epsilon)$ were obtained through Eq. 4 and 5, respectively.

$\sigma=S(1+7)($ Eq. 4$)$

$\varepsilon=\ln (1+7)($ Eq. 5$)$

Where:

$\mathrm{S}=$ Conventional stress or engineering stress;

$1=$ Conventional strain or engineering strain.

The true curve is then transformed into a logarithmic scale $(\log \sigma \times \log \epsilon)$ whose slope in the plastic deformation region, prior to maximum engineering strain (or similarly, before the maximum engineering stress), is the work hardening coefficient.

\subsection{J-integral test}

Six single edge notch bend (SENB) specimens type three points, which were machined from each alloy, have provided the crack opening displacement (COD) tests. The dimensions of the specimens, as well as the other test procedures, were been set according to the plate's thickness, following the appropriate standards (ASTM E399-19, ASTM E1290-08 and BS 7448-1). Thus, the dimensions of the specimens were as follows:

Height, $\mathrm{W}=9 \mathrm{~mm}$; Thickness, $\mathrm{B}=4.5 \mathrm{~mm}$; Length, $\mathrm{L}=60 \mathrm{~mm}$; Span between bending rollers, $\mathrm{S}=40$ $\mathrm{mm}$; Notch $=3.2 \mathrm{~mm}$; Pre-crack, a $=4.2 \mathrm{~mm}$.

The notch was machined with $1 \mathrm{~mm}$ thickness. The length of the fatigue pre-crack was controlled by clip gauge $(632.02 \mathrm{~F}-20, \mathrm{MTS})$, which was assembled to the specimen by wedge-shaped brackets (Figure 2). The pre-cracks were opened in servohydraulic machine (MTS Landmark $100 \mathrm{kN}$ ), applying bending cyclic loading 
at $10 \mathrm{~Hz}$, load ratio $\mathrm{R}=0.1$ and maximum stress intensity factor at the crack tip $\Delta \mathrm{K}$ of $11 \mathrm{MPa} . \mathrm{m} 1 / 2$ (Figure $3)$.

The pre-cracked specimens were subjected to monotonic bending load at $1 \mathrm{~mm} / \mathrm{min}$. The load and crackmouth opening displacement (CMOD) were acquired until reaching the unstable fracture of the specimens. The J-value is calculated by its expression for static cracks.

Figure 2 - Dimensions exhibited on the frontal view of the specimen whose thickness was $4.9 \mathrm{~mm}$.

All results were compared using variance analysis One way ANOVA with significance index p [?] 0.05 .

The fracture micromechanisms were performed by Scanning Electron Microscopy (SEM JEOL Carry Scope JCM-5700).

\section{Results and discussions}

\subsection{Microstructures}

In previous studies, through the combination of microstructural analyses and XRD analyses, it was observed that these alloys present the predominant formation of $\alpha$ " (deformation-induced martensite) and $\beta$ phases after solidification and slow cooling; preponderant retention of $\beta$ phase due to rapid cooling after solution heat treatment and the formation of metastable phases $\alpha$ " during cold forming. Furthermore, aging after cold forming promotes the formation of precipitates predominantly of $\alpha$ phase [9-10].

Figure 3 shows the micrographs representing all the alloys studied. The microstructural analyses of Ti352C and Ti352A alloys (Figures 3(a) and 3(b), respectively) show that cold rolled alloys as well as aged alloys presented the same microstructural aspects. The microstructures consist on elongated primary $\beta$ grains in the rolling direction, $\alpha$ " needles and slip bands originating from cold forming [9].

Through the microstructural analyses of Ti352C and Ti420C alloys (Figures 3(a) and 3(c), respectively) it is possible to verify that the Ti352C alloy has more $\alpha$ " needles in relation to the samples with higher $\mathrm{Nb}$ content. The effect of $\mathrm{Nb}$ on the $\mathrm{Ti}$ alloy is to stabilize the $\beta$ phase [13]. Several studies show that $\mathrm{Nb}$ at $35 \%$ already allows stabilizing the $\beta$ phase depending on the thermomechanical process $[7,9]$. However, the increase of $\mathrm{Nb}$ to $42 \%$ stabilizes more $\beta$.

Figure 4 shows SEM images of the Ti352C alloy microstructure with more details of the slip bands morphology and the deformation-induced martensite phase $(\alpha ")$.

Figure 3 - Metallographic images of alloys (a) Ti352C, (b) Ti352A, (c) Ti420C. Elongated primary $\beta$ grains in the rolling direction, $\alpha$ " phase disperses amongst the slip bands. The amount of $\alpha$ " phase is clearly higher in the alloy with lower $\mathrm{Nb}$ content. The aged alloy has the same microstructural characteristics as the cold rolled alloy.

Figure 4 - SEM image of the Ti352C alloy showing slip bands network within the $\beta$ grains and $\alpha$ " needles.

\subsection{Work hardening coefficient}

The work hardening coefficient is a measure of an alloy's ability to promote slip bands [14-15]. The main purpose of this approach in the present study was to prove the microstructural results. Figure 5 shows a logarithmic true curve representative of all alloys, which was used to obtain the coefficient. Figure 6 shows the results of the work hardening coefficient for TiNbSn alloys influenced by the $\mathrm{Nb}$ and $\mathrm{Sn}$ content, and aged. Well, as the work hardening coefficients were similar in cold rolled alloys, regardless of the alloy content, this proves that the difference in the microstructures seen in the metallographic analysis of Fig. 3 is the greater amount of $\alpha$ " of the $35 \mathrm{Nb}$ alloy, since the amount of the slip bands must be very similar.

Figure 5- Logarithmic true curve representation of the Ti352A alloy to obtain the work hardening coefficient.

It can be observed that both cold rolled alloys and aged alloys present statistically similar values of work hardening coefficients. In the aged alloys there was an increase in the work hardening coefficient in relation 
to the rolled alloys, with significant differences for the alloys of Nb-42\%. This is due to the appearance of precipitates in aging, as explained by Azevedo et. al. [9], which promote greater restriction to the movement of dislocations, causing a higher rate of stress increase due to plastic deformation.

The literature indicates that the addition of Sn in larger amounts (5 and 7.5\%) causes reduction of ductility and work hardening coefficient. Comparing the work hardening coefficient of the hot rolled Ti352 alloy studied by Griza et al. [8] with the results of this same cold and aged rolled alloy produced in this study, it is possible to note that there was no significant change in the work hardening coefficient. Therefore, it can be concluded that the addition of Sn up to $2.5 \%$ does not influence the work hardening coefficient, regardless of the used manufacture thermomechanical routes.

Figure 6 - Work hardening coefficient for the rolled and aged TiNbSn alloys.

\subsection{J-integral test}

The Figure 7 shows a CMOD curve of the Ti422C alloy, representative of all the alloys analyzed, where we can observe the two different areas that were used for the J calculation.

Figure 7 - CMOD curve representation of the Ti422C alloy. The two different areas (elastic and plastic) are highlighted.

Figure 8 shows the values of J-integral for the alloys. It was observed that the $\mathrm{Nb}$ increase promoted the significant increase of J. This should be related to $\beta$ stabilization, which the literature indicates that it has greater toughness than $\alpha$ and $\alpha$ ", as well as other phases that occur in $\beta$-Ti alloys. This is in accordance with our microstructural evaluation, from which we find more $\alpha$ " in the Nb-35\% alloy.

The Ti422C and Ti420C alloys presented the highest toughness values, with no significant difference between them. This indicates that the Sn- $2.5 \%$ increase did not influence the toughness of the cold rolled alloys. The Ti352C alloy presented lower J-integral compared to the previous two alloys. This indicates that the $\mathrm{Nb}$ content increasing from 35 to $42 \%$ impacts positively the toughness of these Ti alloys. Well, as the increase in $\mathrm{Nb}$ stabilizes $\beta$, this should have a positive impact on the toughness increase of the alloys.

The aged alloys had a decrease in J-integral compared to cold rolled alloys. The aging causes ductility and toughness decrease, and it increases the mechanical strength and Young's modulus [9 - 11]. In addition, for aged alloys, the difference in toughness among them is more evident. The Nb-35\% alloy has low J-integral. Increasing to Nb-42\% (Ti420A alloy), we noticed significant increase of J-integral.

By observing the Ti422A and Ti420A alloys, Sn influences significantly J values, since the Ti422A alloy was the one with the highest J value among the aged alloys. So, we can conclude that the Sn in solution favored the toughness for the aged alloy, because it should stabilize more $\beta$ and reduce the formation of precipitates, obtaining fewer barriers to dislocation.

Figure 8 -J-integral values.

The analyses performed in the flat zone of propagation of the fractured specimens after tests of J-integral allowed to observe the predominant fracture micromechanisms and their morphologies. Figure 9 shows the fractographic details by SEM of the alloys' flat fracture regions. The coalescence of shallow microcavities is observed on the alloys tested in both manufacturing processes, characteristic of the fracture behavior of low toughness alloys.

These fractographs indicate that the aged alloys had a decrease in the size of dimples, which are shallower when compared to the only cold rolled alloys. The dimples are formed from the difference of ductility between the matrix and the precipitates, which allows the interfacial separation (nucleation), the growth and coalescence of the microcavities. The formation of these small and shallower voids is related to the presence of precipitates.

The interfacial separation between matrix and precipitates due to differences in their deformation behavior allows microcavities to grow and coalesce. The thin precipitates of the aged alloys provide the formation of 
the smaller and shallower dimples, which coalesce after little deformation due to the precipitates dispersion and, consequently, cause the fracture of lower ductility.

Through the SEM fracture surface of aged alloys, it is possible to observe that the increase in Nb causes an increase in the size of the coalescence micromechanisms of microcavities [16]. This is related to toughness, since, for example, the Ti352A alloy has lower toughness and, thinner and shallower microcavities than the other alloys (Figure 9).

Figure 9 - SEM images of the alloys: (a) Ti352C, (b) Ti352A, (c) Ti422C, (d) Ti422A, (e) Ti420C and (f) Ti420A. The elongated primary $\beta$ grains are in the rolling direction. Aged alloys presented coalescence of small and less deep microcavities compared to alloys subjected to cold rolling.

\section{Conclusions}

The present study aimed to observe the fracture toughness as a function of the J-integral of the TiNbSn alloys as a function of the alloying element content and thermomechanical treatment. The following conclusions were obtained:

- The cold rolled alloys with the highest $\mathrm{Nb}$ content were the ones with the highest toughness. The addition of $\mathrm{Nb}$ in these alloys is beneficial for toughness because $\mathrm{Nb}$ stabilizes the $\beta$ phase.

- In alloys with lower $\mathrm{Nb}$ content, cold rolling causes a greater amount of $\alpha$ ", and this disfavors toughness.

- The aging caused a reduction in the alloys toughness, since the formation of precipitates in aging causes shallower and smaller dimples in the fracture, which causes less toughness.

- The addition of $2.5 \% \mathrm{Sn}$ did not influence the toughness of the Ti-Nb cold rolled alloys.

Acknowledgements

The authors would like to thank the financial support of CAPES and CNPq.

References

[1] K. Miura, N. Yamada, S. Hanada e T. K. Jung, "The bone tissue compatibilitty of a new Ti-Nb-Sn alloy with a low young's modulus," Acta Biomaterialia, vol. 7, pp. 2320-2326, 2011.

[2] Y. L. Hao, S. J. Li, S. Y. Sun e R. Yang, "Effect of Zr and Sn on Young's modulus and superelasticity of Ti-Nb-based alloys," Materials Science Engineering A, vol. 441, pp. 112-118, 2006.

[3] S. X. Liang, X. J. Feng, L. X. Yin, M. Z. Ma e R. P. Liu, "Development of a new $\beta$ Ti alloy with low modulus and favorable plasticity for implant material," Materials Science and Engineering: C, vol. 61, pp. 338-343, 2016.

[4] Y. P. Hou, S. Guo, X. L. Qiao, T. Tian, Q. K. Meng, X. N. Cheng e X. Q. Zhao, "Origin of ultralow Young's modulus in a metastable $\beta$-type Ti-33Nb-4Sn alloy," Journal of the Mechanical Behavior of Biomedical Materials, vol. 59, pp. 220-225, 2016.

[5] Y. F. Zheng, B. L. Wang, J. G. Wang e L. C. Zhao, "Corrosion behavior of Ti-Nb-Sn shape memory alloys in different simulated body solutions," Materials Science and Engineering A, vol. 438, pp. 891-895, 2006.

[6] Thiago Figueiredo Azevedo, Carlos Eduardo Celestino de Andrade, Silvando Vieira dos Santos, Abraão Santos Silva, Sandro Griza, "Fatigue and corrosion-fatigue strength of hot rolled Ti35Nb2.5Sn alloy", Materials \& Design Volume 85, 15 November 2015, Pages 607-612.

[7] Y. L. Zhou e D. M. Lou, "Microstructures and mechanical properties of Ti-Mo alloys cold-rolled and heat treated" Materials Characterizations, vol. 62, pp. 931-937, 2011.

[8] S. Griza, D. H. G. d. S. Sá, W. W. Batista, J. C. G. d. Blas e L. C. Pereira, "Microstructure and mechanical properties of hot rolled TiNbSn alloys," Materials and Design, vol. 56, pp. 200-208, 2014. 
[9] Thiago Figueiredo Azevedo, Tiago Nunes Lima, Juan Garcia de Blas, Luiz Carlos Pereira, Sandro Griza, "The mechanical behavior of TiNbSn alloys according to alloying contents, cold rolling and aging", Journal of the Mechanical Behavior of Biomedical Materials, Volume 75, 2017, Pages 33-40,

[10] M. Niinomi, M. Nakai e J. Hieda, "Development of new metallic alloys for biomedical applications," ACTA BIOMATERIALIA, vol. 8, $\mathrm{n}^{\mathrm{o}}$ 11, pp. 3888-3903, 2012.

[11] Thiago Figueiredo Azevedo, Tiago Nunes Lima, Matheus Duarte Macedo, Juan Garcia de Blas, Sandro Griza; "Fracture mechanics behavior of TiNbSn alloys as a function of alloy content, cold working and aging"; Engineering Fracture Mechanics Vol. 229; 2020.

[12] Xian-Kui Zhu, James A. Joyce; Review of fracture toughness (G, K, J, CTOD, CTOA) testing and standardization; Engineering Fracture Mechanics Vol. 85 pp - 1-46; 2012.

[13] Zhang, L.; et al.; "Effect of $\mathrm{Nb}$ addition on microstructure, mechanical properties and castability of $\beta$-type Ti-Mo alloys"; Journal of Trans. Nonferrous Met. Soc. China V.25 pp. 2214-2220; 2015;

[14] D.L. Davidson, K.S. Chan; Slip line formation during tensile straining experiments at ambient temperature in a Nb-Cr-Ti alloy; Materials Science and Engineering A Vol. 282 pp - 100-108; 2000;

[15] Hiroshi Hamasaki, Tatsuya Ohno, Takashi Nakano, Eiichiro Ishimaru; Modelling of cyclic plasticity and martensitic transformation for type 304 austenitic stainless steel; International Journal of Mechanical Sciences, pp - 536-543; 2018;

[16] Chang, L.L., et al.; "In-situ investigation of stress-induced martensitic transformation in Ti-Nb binary alloys with low Young's modulus"; Materials Science \& Engineering A Vol.651 pp-442-448; 2016;

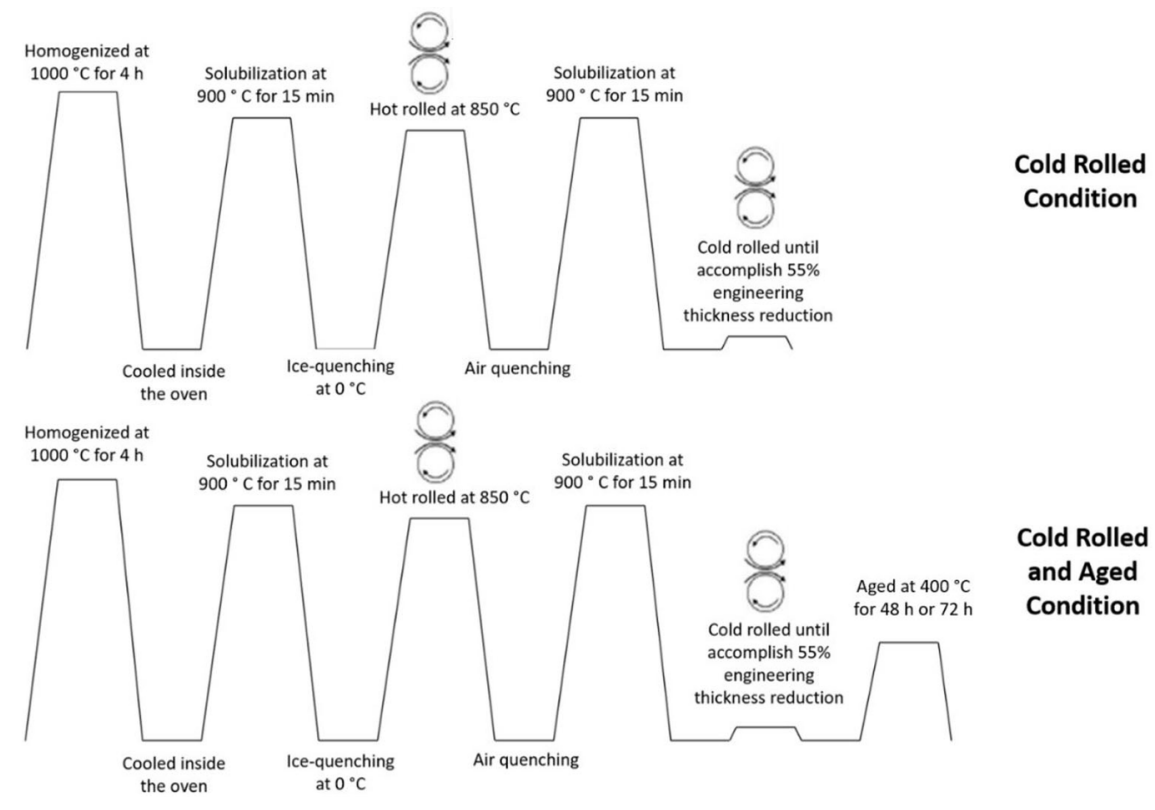



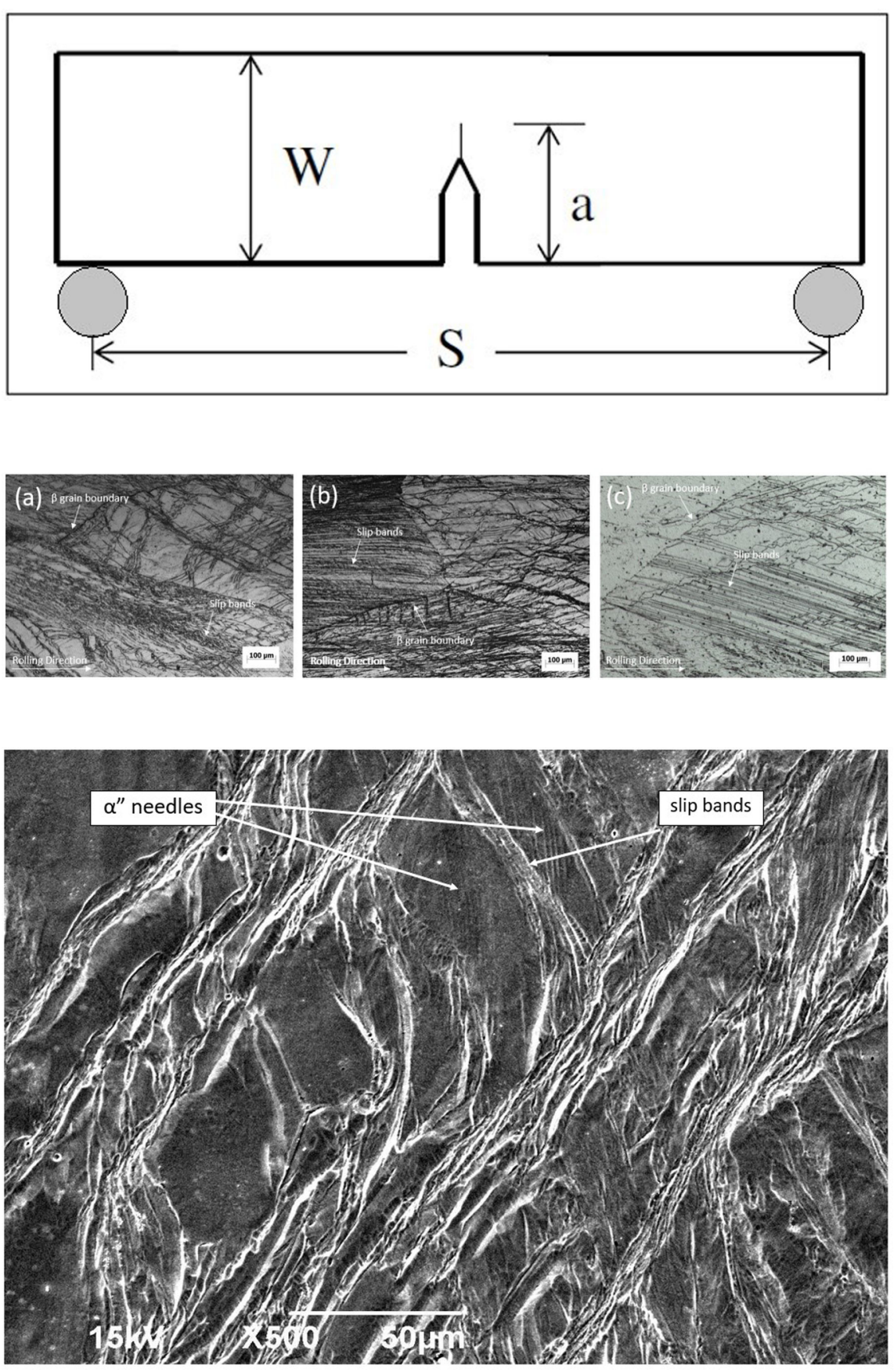

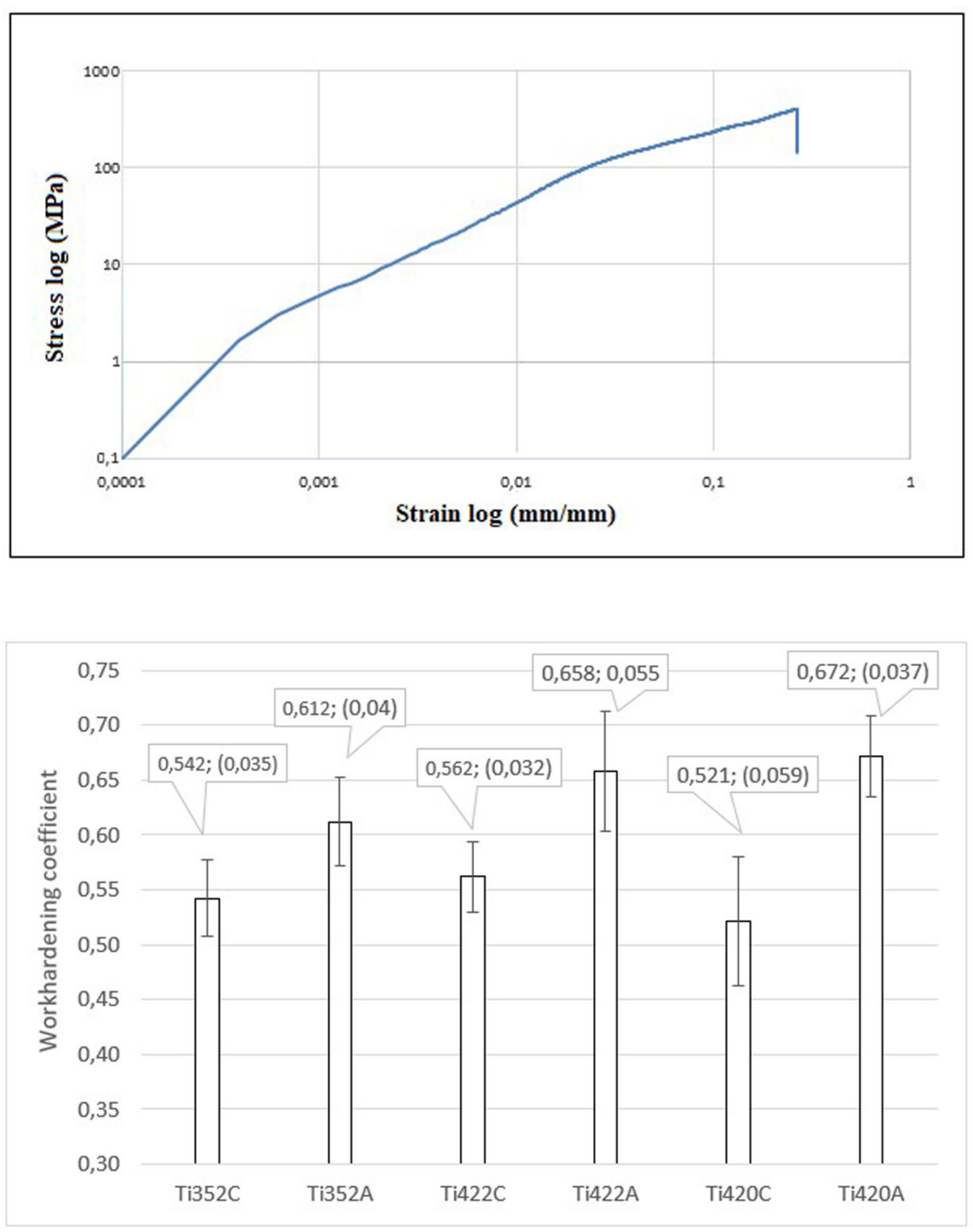

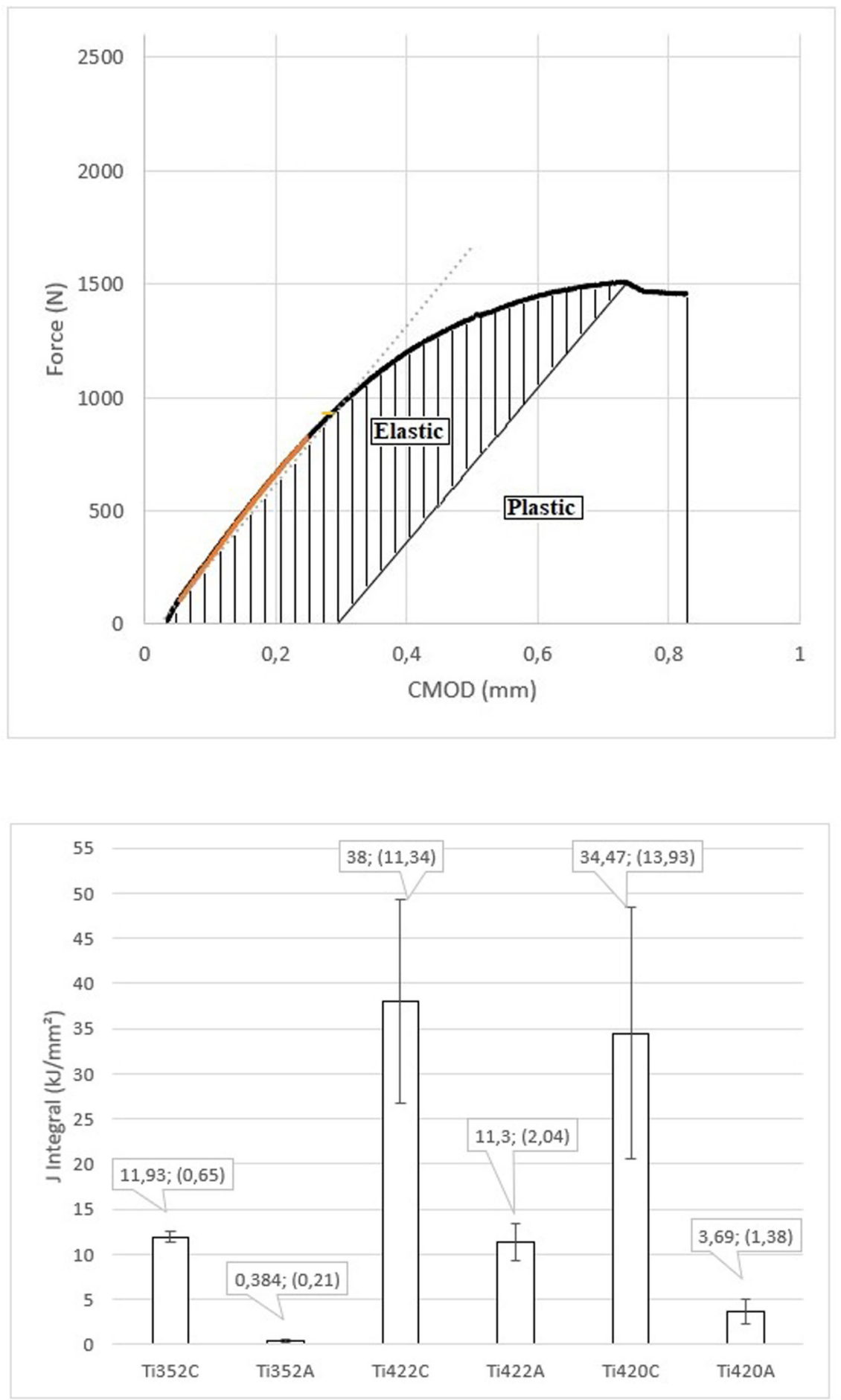

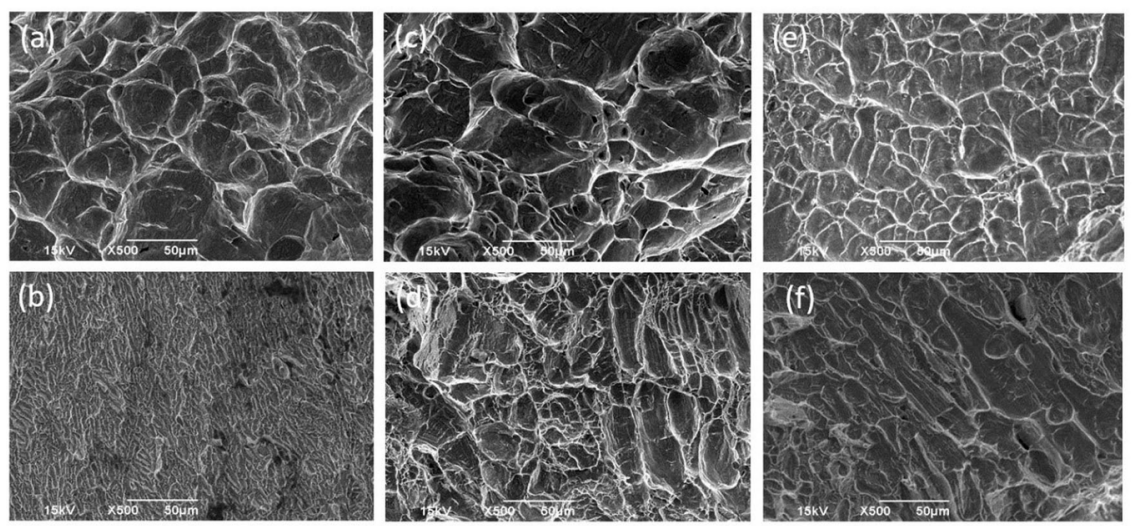